$-20^{\circ} \mathrm{C}$ until being assayed for serum and plasma potassium concentrations by flame photometry (within batch $\mathrm{SD}=0.03 \mathrm{mmol} / \mathrm{l}$ ). The Mann-Whitney U test and Spearman's rank correlation coefficient were used in statistical analysis.

The median (range) difference in potassium concentration between serum and plasma in the 43 patients with rheumatoid arthritis was $0.3(0 \cdot 1-$ $1 \cdot 3) \mathrm{mmol} / \mathrm{l}$, which was significantly greater $(\mathrm{p}<0.001)$ than that in the 21 controls with arthritis $(0.2(0$ $0.4) \mathrm{mmol} / \mathrm{l})$ and the 28 normal subjects $(0.2(0$ $0 \cdot 4) \mathrm{mmol} / \mathrm{l}$ ). Serum creatinine and plasma potassium concentrations and the white cell count were similar in the three groups, but the platelet count was significantly $(p<0.001)$ higher in the patients with rheumatoid arthritis (median (range) 366 (165$1260) \times 10^{3} / 1$ v $287(122-444) \times 10^{3} / 1$ in the controls with arthritis and $305(192-440) \times 10^{3} / 1$ in the normal subjects). The difference in potassium concentration between serum and plasma in the patients with rheumatoid arthritis correlated with their platelet count (figure) $(\mathrm{r}=0.64, \mathrm{p}<0.001)$.

\section{Comment}

We are not aware of other reports of pseudohyperkalaemia occurring in conditions such as rheumatoid arthritis. We found that in normal subjects the median serum potassium concentration was $0.2 \mathrm{mmol} / \mathrm{l}$ higher than the plasma potassium concentration, which confirms a previous report. ${ }^{+}$We found a similar difference in our control group of patients with arthritis who were taking non-steroidal antiinflammatory drugs, which excludes these as the cause of the pseudohyperkalaemia. In contrast, the difference in concentrations was significant in the patients with rheumatoid arthritis, with values of $1.5 \mathrm{mmol} / \mathrm{l}$ being recorded (case 2 ). The pseudohyperkalaemia may have been due to the raised platelet count in view of the correlation between it and the difference between serum and plasma potassium concentrations.

Failure to recognise pseudohyperkalaemia in our patients led to errors in management: one patient was given treatment to lower her potassium concentration

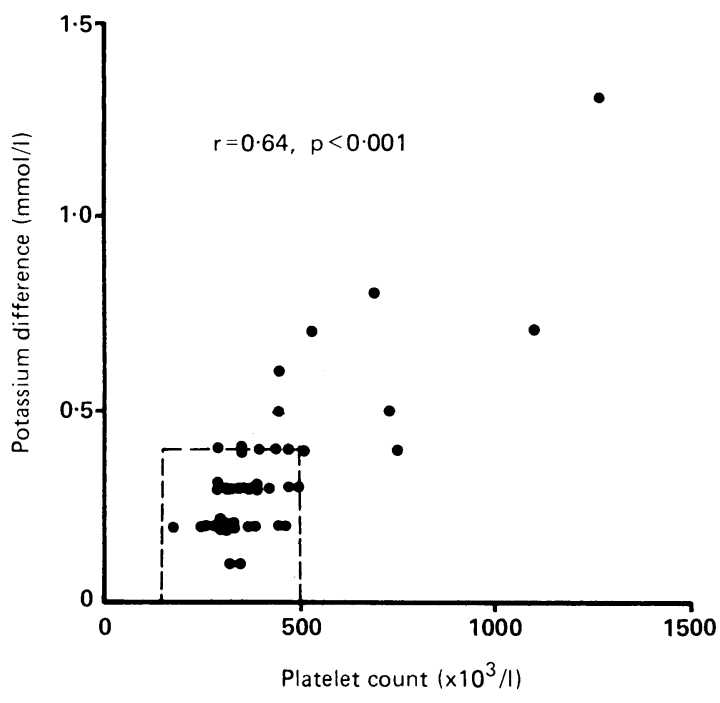

Relation between platelet count and difference in potassium concentration between serum and plasma (potassium difference) in 43 patients with rheumatoid arthritis. Area enclosed by broken line indicates reference ranges for both variables in normal subjects

and one had her treatment with a non-steroidal antiinflammatory drug stopped unnecessarily. Our data suggest that pseudohyperkalaemia may be common and often overlooked in active rheumatoid arthritis. It may easily be confirmed by concurrent measurements of serum and plasma potassium concentrations, a difference $>0.40 \mathrm{mmol} / \mathrm{l}$ being diagnostic.

We thank Drs Stephanie Armstrong and Alison Trainer for help with collecting the blood samples.

1 Hartmann RC, Auditore JV, Jackson DP. Studies on thrombocytosis. I. Hyperkalemia due to release of potassium from platelets during coagulation. f Clin Invest 1955;37:699-707.

2 Bronson WR, DeVita VT, Carbone PP, Cotlove E. Pseudohyperkalemia due to release of potassium from white blood cells during clotting. $N$ Engl $f$ Med 1966;274:369-75.

3 Kerr DJ, McAlpine LG, Dagg JH. Pseudohyperkalaemia. Br Med f 1985;291 890-1.

4 Young DS. Biological variability. In: Brown SS, Mitchell FL, Young DS, eds. Chemical diagnosis of disease. 1st ed. Amsterdam: Elsevier, 1979:1-113.

(Accepted 21 April 1988)

\title{
Relative risks of different types of contact lenses
}

\section{W A Franks, G G W Adams, J K G Dart, D Minassian}

Moorfields Eye Hospital, London WC1 7AN

W A Franks, FRCS, registrar

G G W Adams, FRCs, registrar

Institute of Ophthalmology,

University of London

J K G Dart, FRCs, lecturer

D Minassian, FRCS, senior

lecturer

Correspondence to: Miss Franks.
There have been few studies to determine the size of the problem of eye disease related to contact lenses in a community or to compare the risks of complications associated with different types of lenses. ${ }^{2}$ We therefore performed a case-control study to estimate the relative risks.

\section{Patients, methods, and results}

All patients who wore contact lenses and attended the High Holborn branch of Moorfields Eye Hospital between 1 January and 31 March 1986 were included in the study. Disorders related to contact lenses were diagnosed from previously agreed clinical criteria; the conditions were grouped for analysis according to pathogenesis.

Of 393 patients ( 152 men, 241 women) who wore contact lenses, 329 had problems related to wearing lenses; 64 patients who wore lenses attended for an unrelated ocular problem. One hundred and ninety patients wore daily wear soft lenses, 45 extended wear soft lenses, 100 polymethylmethacrylate hard lenses, and 58 gas permeable hard lenses. Two hundred and seventeen patients were aged 20-29. Of the 393, 367 patients obtained their lenses privately and 26 were fitted by hospital eye departments. Ten patients wore lenses for aphakia, six for keratoconus, and 14 for high myopia. The rest wore lenses in preference to spectacles for low refractive errors.

The main groups of conditions seen were metabolic (principally corneal hypoxia), toxic and hypersensitivity reactions, corneal abrasions, and infections. Five cases of bacterial keratitis were diagnosed, all in patients who wore soft lenses. Problems related to contact lenses accounted for $10 \%$ of all attendances at the casualty department.

The relative risk associated with each type of lens for a disorder was estimated by calculating the odds ratio from contingency tables. Hard lenses were hypothesised to have the least risk of complications before the analysis, for which the polymethylmethacrylate hard lens was taken as the referent, with a baseline risk of 1.0 . The risks for other lenses were estimated as multiples of this. The significance of the increasing risks was estimated with the Mantel-Haenszel $\chi^{2}$ test of trend. ${ }^{3}$ The overall risk for soft lenses compared with 
Relative risks of disorders related to contact lenses for each type of lens

\begin{tabular}{|c|c|c|c|c|c|}
\hline I.ens type & $\begin{array}{l}\text { No of } \\
\text { cases }\end{array}$ & $\begin{array}{l}\text { No of } \\
\text { controls }\end{array}$ & $\begin{array}{c}\text { Relative } \\
\text { risk }\end{array}$ & $\begin{array}{c}95 \% \text { Confidence } \\
\text { interval }\end{array}$ & $\begin{array}{l}\text { Significance } \\
\text { of trend }\end{array}$ \\
\hline \multicolumn{6}{|c|}{ Metabolic disorders } \\
\hline Hard: & & & & & \multirow{6}{*}{$\mathrm{p}<0.05$} \\
\hline Polymethylmethacrylate & 8 & 92 & $1 \cdot 0$ & & \\
\hline Gas permeable & 8 & 50 & $1 \cdot 8$ & 0.6 to 5.2 & \\
\hline \multicolumn{5}{|l|}{ Soft: } & \\
\hline Daily wear & 28 & 162 & $2 \cdot 0$ & 0.9 to 4.5 & \\
\hline Extended wear & 10 & 35 & $3 \cdot 3$ & $1 \cdot 2$ to $8 \cdot 7$ & \\
\hline \multicolumn{6}{|c|}{ Toxic or hypersensitivity reactions } \\
\hline Hard: & & & & & \multirow{6}{*}{$\mathrm{p}<0.001$} \\
\hline Polymethylmethacrylate & 7 & 93 & $1 \cdot 0$ & & \\
\hline Gas permeable & 5 & 53 & $1 \cdot 25$ & 0.4 to $4 \cdot 2$ & \\
\hline \multicolumn{5}{|l|}{ Soft: } & \\
\hline Daily wear & 48 & 142 & $4 \cdot 5$ & $2 \cdot 1$ to $9 \cdot 8$ & \\
\hline Extended wear & 9 & 36 & $3 \cdot 3$ & $1 \cdot 2 \quad 109 \cdot 2$ & \\
\hline \multicolumn{5}{|c|}{ Abrasions } & \multirow{7}{*}{$\mathrm{p}<0.001$} \\
\hline Hard: & & & & & \\
\hline Polymethylmethacrylate & 21 & 79 & $1 \cdot 0$ & & \\
\hline Gas permeable & 14 & 44 & $1 \cdot 2$ & 0.6 to 2.6 & \\
\hline \multicolumn{5}{|l|}{ Soft: } & \\
\hline Daily wear & 12 & 178 & $0 \cdot 25$ & 0.1 to 0.5 & \\
\hline Extended wear & 1 & 44 & 0.09 & 0.02 to 0.45 & \\
\hline \multicolumn{5}{|c|}{ Infections } & \multirow{7}{*}{$\mathrm{p}=0 \cdot 24$} \\
\hline Hard: & & & & & \\
\hline Polymethylmethacrylate & 13 & 87 & $1 \cdot 0$ & & \\
\hline Gas permeable & 3 & 55 & $0 \cdot 37$ & 0.1 to 1.3 & \\
\hline & \\
\hline Daily wear & 15 & 175 & 0.57 & 0.3 to 1.3 & \\
\hline Extended wear & 13 & 32 & $2 \cdot 7$ & $1 \cdot 2$ to $6 \cdot 4$ & \\
\hline \multicolumn{5}{|c|}{ All disorders } & \multirow{7}{*}{$\mathrm{p}<0 \cdot 01$} \\
\hline Hard: & 122 & 36 & $1 \cdot 0$ & & \\
\hline Polymethylmethacrylate & 76 & 24 & 1.0 & & \\
\hline Gas permeable & 46 & 12 & $1 \cdot 2$ & 0.6 to $2 \cdot 7$ & \\
\hline Soft: & 207 & 28 & $2 \cdot 2$ & & \\
\hline Daily wear & 164 & 26 & $2 \cdot 0$ & 1.1 to 3.7 & \\
\hline Extended wear & 43 & 2 & $6 \cdot 8$ & 1.8 to 2.6 & \\
\hline
\end{tabular}

that for hard was calculated identically by comparing the number of patients who had complications with those who had unrelated disorders. These controls were used to estimate the proportions of each lens type used in our catchment area. The significance was estimated with the $\chi^{2}$ test, and $95 \%$ confidence intervals were derived.' The table shows these results.

\section{Comment}

The number of patients attending the casualty department for problems related to contact lenses was four times higher than that in a previous survey at the City Road branch of Moorfields Eye Hospital. ${ }^{+}$In our study a higher proportion of patients wore soft lenses and twice as many extended wear soft lenses. The increase in attendance is probably due to a larger number of wearers of contact lenses in the catchment area of this department and to a higher incidence of problems experienced with soft contact lenses. Recent studies have shown a higher risk of complications, particularly microbial keratitis, for soft lenses compared with gas permeable hard lenses.

The risk for all complications was $2 \cdot 2$ times greater for all soft lenses compared with that for all hard lenses. Compared with the lowest risk lens, the polymethylmethacrylate hard lens, the risk was $2 \cdot 0$ times greater for daily wear soft lenses, rising to 6.8 times greater for extended wear soft lenses.

The increased risk of wearing soft lenses shown in this study supports a growing consensus of opinion, but the controls are hospital based, and studies with population based controls are needed to confirm these findings. Those considering wearing contact lenses should be warned of the increased risks before opting for soft lenses.

1 Graham CM, Dart JKG, Bucklev RJ. Extended wear hydrogel and daily wea hard contact lenses for aphakia. Ophthalmologv 1986;93:1489-94.

2 Shein O, Hibberd P, Kenyon KR. Contact lens complications: incidental or epidemic? Am 7 Ophthalmol 1986;102:116-7.

3 Mantel N. Chi-square tests with one degree of freedom; extensions of the Mantel-Haenszel procedure. Joumal of the American Statistical Association 1963;58:690-700.

4 Barry PJ, Ruben M. Contact lens injuries. An analysis of 217 consecutive patients presenting to Moorfields casualty department. Contact Lens foumd 1980;9:6-10.

5 Dart JKG. Bacterial keratitis in contact lens users. Br.Med 7 1987:295:959-60.

Accepted 12 April 1988

\section{Intermittent torsion of the testis}

\author{
Thomas A Creagh, Thomas E McDermott, \\ Peter A McLean, Anthony Walsh
}

\begin{abstract}
Department of Urology, Charitable Infirmary,

Dublin

Thomas A Creagh, FRCSI, research registrar

Thomas E McDermott, FRCSI, consultant urologist Peter A McLean, FRCSI, consultant urologist Anthony Walsh, FRCSI, consultant urologist
\end{abstract}

Correspondence to: $\mathrm{Mr} \mathrm{T}$ A Creagh, Beaumont Hospital, PO Box 1297, Beaumont Road, Dublin, Ireland.
Intermittent torsion of the testis, although recognised as early as $1895,^{1}$ receives little attention in reports on the acute scrotum. Its recognition and treatment, however, may prevent subsequent torsion and will relieve the unpleasant symptom of recurrent testicular pain. To rectify this apparent oversight we reviewed 30 patients with recurrent testicular pain seen in the urology outpatient department of the Charitable Infirmary, Jervis Street, Dublin over 10 years.

\section{Patients, methods, and results}

Between January 1973 and December 198230 young men aged between 12 and 33 years were referred to our outpatients department because of recurrent testicular pain. These patients had experienced, on more than one occasion, unilateral scrotal pain of sudden onset and short duration (less than two hours) that resolved spontaneously. On examination the affected testicle had a horizontal lie. A diagnosis of intermittent torsion of the testis was made, and elective bilateral orchidopexy was performed, under general anaesthesia, through a scrotal incision with three size 00 chronic catgut sutures. Twenty seven patients underwent orchidopexy and 19 were available for review.
Three patients developed acute torsion while on the waiting list for admission. The 27 remaining patients underwent orchidopexy and at surgery 22 were noted to have testes of normal appearance, four had evidence of torsion of the appendix testis, and one had an atrophic testis. A biopsy specimen of the atrophic testis showed evidence of previous ischaemia. Nineteen patients attended for follow up interview and examination. Eighteen patients reported that the operation had relieved the symptoms that they had sought treatment for. Seventeen patients had normal testes and one patient had an atrophic testis. One patient had subsequently developed acute torsion despite earlier orchidopexy.

\section{Comment}

Intermittent torsion of the testis is a definite entity with a characteristic history of more than one attack of unilateral scrotal pain of sudden onset and short duration (less than two hours) that resolves spontaneously. On physical examination the testis on the affected side has a horizontal lie when the patient is standing. Further evidence of its existence is that testicular fixation will relieve the presenting symptom of recurrent testicular pain, as was the case for 18 of the 19 patients available for review in this study.

This diagnosis is important not only because it allows relief of unpleasant symptoms but also because of its relation to acute torsion of the spermatic cord. In this series three patients developed acute torsion while awaiting orchidopexy and one patient developed torsion despite a previous orchidopexy, resulting in an 